\title{
Modelling the Dynamics of Market Shares in a Pooled \\ Data Setting: Econometric and Empirical Issues
}

Forthcoming in Applied Economics

Felicitas Nowak-Lehmann D. ${ }^{\mathrm{a}^{*}}$, Dierk Herzer ${ }^{\mathrm{b}}$, Sebastian Vollmer ${ }^{\mathrm{a}}$, and Inmaculada Martínez-Zarzoso ${ }^{c}$

${ }^{a}$ Ibero-America Institute for Economic Research at the University of Goettingen, Goettingen, Germany

${ }^{\mathrm{b}}$ Goethe-University of Frankfurt, Frankfurt am Main, Germany

${ }^{\mathrm{c}}$ University of Jaume I, Castellón, Spain

The objective of this paper is twofold. First, it is to study the applicability of the widely used Autoregressive Distributed Lag Model (ARDL) in a pooled data setting. Second, it is to analyse Chile's market shares in the EU during the period 1988 to 2002, pointing to application problems that might jeopardise the model and searching for estimation methods that deal with the problem of inter-temporal and cross-sectional correlation of the disturbances. To estimate the coefficients of the ARDL model, Feasible Generalised Least Squares (FGLS) is utilised within the Three-Stage Least Squares (3SLS) and the non-standard Generalised Method of Moments (GMM) frameworks. A computation of errors is added to highlight the susceptibility of the model to problems related to the underlying model assumptions.

Keywords: dynamic panel data model; standard autoregressive distributed lag model; pooled Three-Stage Feasible Generalised Least Squares estimation; non-standard panel GMM estimation; market shares JEL: F14; F17; C23

\section{Introduction}

\footnotetext{
*Corresponding author. E-mail: fnowak@uni-goettingen.de
} 
In this paper, a standard Autoregressive Distributed Lag Model (ARDL) is utilised to estimate the dynamics of Chile's market shares in the EU market. This dynamic model has been adapted from studies of Balestra and Nerlove (1966), Baltagi and Levin (1986), Arellano and Bond (1991), Blundell et al. (1992), Islam (1995), and Ziliak (1997), Kim et al. (2003) among others. Cable (1997) applied an ARDL to market share behaviour and mobility in the UK daily newspaper market. A common feature of all these studies (and many more of this kind) is that the dynamic relationship between dependent and independent variables is captured by a lagged dependent variable, thus leading to an autoregressive distributed lag model. This is the standard dynamic model that is applied to panel data, as described in Baltagi (2005).

The main aim of this paper is to examine the applicability of the ARDL from both a theoretical and an empirical point of view. From a theoretical perspective, we analyse the structure and origin of this widely used autoregressive distributed lag model. From an empirical perspective, we illustrate estimation problems of the ARDL with an empirical application to Chile's market shares in the EU market. We differentiate among three types of caveats that can be lodged. The first is theoretical and deals with the underlying assumptions of the ARDL and the underlying geometric lag structure. The second caveat deals with the time-series properties of the data and the autocorrelation problem present in most panel data sets. The third caveat centres around the endogeneity of the lagged dependent variable on the right-hand side and the endogeneity of standard instrumental variables in the presence of serial autocorrelation. To tackle these estimation problems, the dynamic pooled data model is estimated by both the Three Stage Least Squares (3SLS) and non-standard Generalised Method of Moments (GMM) methods, in combination with Feasible Generalised Least Squares 
(FGLS) and Seemingly Unrelated Regression (SUR) to deal with the problems of endogeneity and autocorrelation of the residuals across countries and over time.

Critically examining the preconditions of the model, studying its applicability to panel data, and highlighting the inherent problems of the ARDL are the main tasks of this paper. We differ from other dynamic panel studies in that we take into account the time-series properties of the variables, employ non-standard estimation techniques, and conduct an error analysis. To our knowledge, this is the first study to apply such procedures.

The paper is set up as follows. In Section II, applicability issues and estimation problems of the ARDL are discussed. Moreover, the derivation of the model and the underlying assumptions of the ARDL are analysed and combined estimation techniques to solve at least some of the estimation problems arising in a pooled data setting are then proposed. In Section III, we set up a simple dynamic market-share model for Chilean exporters to the EU and study the empirical applicability of the ARDL. Section IV presents our estimation results and an error analysis. Section V concludes.

\section{The ARDL model in a panel/pooled data setting}

The most widely used dynamic model for panel data is the first-order autoregressive distributed lag model with only a lagged dependent variable capturing the impact of current and lagged explanatory variables. For simplicity this will be called a simple autoregressive distributed lag model ${ }^{1}$ (ARDL). The Panel ARDL (see Baltagi, 2005) is of the following form:

$$
y_{i t}=a+b_{0} x_{1 i t}+c_{0} x_{2 i t}+\ldots+q_{0} x_{p i t}+\lambda y_{i t-1}+u_{i t}
$$

\footnotetext{
${ }^{1}$ This is identical with the geometric lag model. The more complicated type of autoregressive distributed lag models corresponds to the transfer function model, also known as ARMAX model (for a good description, see Greene, 2000)
} 
where $i=1, \ldots, N, t=1, \ldots, T, a$ is a common intercept, $b_{0}, c_{0}, \ldots, q_{0}$ are the impact multipliers, $\lambda$ is the adjustment parameter, and $\mu_{i t}=\mu_{i}+v_{i t}$. The two components of the error term are independent of each other and among themselves so that $\mu_{i} \sim \operatorname{IID}(0$; $\left.\sigma_{\mu}^{2}\right)$ and $v_{i t} \sim \operatorname{IID}\left(0 ; \sigma_{v}^{2}\right)$ hold. This implies that autocorrelation of $v_{i t}$ is assumed away. The simple ARDL model has become the most popular of all the dynamic models given that the lagged reaction between dependent and explanatory variables is captured in a single parameter, which is known as the adjustment parameter $\lambda$. This parameter expresses the reaction between $y_{i t}$ and $y_{i t-1}$ explicitly and the reaction between $y_{i t}$ and $x_{1 i t}$, $\ldots, x_{1 i t-k}, \ldots, \mathrm{x}_{\text {pit }}, \ldots, x_{\text {pit-k }}$ implicitly. $\lambda$ 'summarises' the impact of all $p$-independent variables. In a panel or pooled data context, the ARDL can exist in two forms: the random-effects $(\mathrm{RE})$ form and the fixed-effects $(\mathrm{FE})$ form.

The advantage of the ARDL is that the number of lag coefficients to be estimated reduces to $b_{0}, . ., q_{0}$ and $\lambda$ and that all impact-coefficients $b_{1}, q_{k}$ can be easily computed according to the general formula: $b_{\text {lag }}=b_{0} \lambda^{\text {lag }}$, thus generating: $b_{1}=b_{0} \lambda^{1}, b_{2}$ $=b_{0} \lambda^{2}$. A further advantage of the ARDL is that it is linear in its coefficients, thus allowing the application of linear estimation techniques.

To estimate the panel $\mathrm{ARDL}^{2}$, various GMM estimators based on first differencing were developed by Holtz-Eakin, Newey, and Rosen (1988), Arellano and Bond (1991), Arellano and Bover (1995), Blundell and Bond (1998), and Keane and Runkle (1992). These methods only ensure unbiased and consistent estimates if the $v_{i t}$ are not auto-correlated.

Besides, the ARDL can be accompanied by two categories of problems that have not been dealt with in the dynamic panel literature. The first is related to the underlying 
model and its very restrictive assumptions. The second has to do with the time-series properties of the variables and the high likelihood of autocorrelation of the disturbances that renders the application of standard GMM techniques inappropriate. ${ }^{3}$ We discuss these problems in the following two subsections.

The underlying model, the Koyck transformation, and the ARDL assumptions

Koyck (1954) was the first to show how an ARDL model (Equation 1) can be obtained from a geometric lag model:

$$
y_{i t}=a_{i}+b_{0} \lambda^{0} x_{1 i t}+\ldots+b_{0} \lambda^{k} x_{1 i t-k}+\ldots+q_{0} \lambda^{0} x_{p i t}+\ldots+q_{0} \lambda^{k} x_{p i t-k}+v_{i t},
$$

where $0<\lambda<1, b_{k}=b_{0} \lambda^{k}$ denotes the impact of a change that happened $\mathrm{k}$ periods ago, and $\lambda$ is the same for all regressors $x_{1 i t}, \ldots, x_{p i t}$. This transformation is called Koyck (lag) transformation. Equation 2 lagged by one period and multiplied through with $\lambda$ gives:

$$
\begin{aligned}
\lambda y_{i t-1}= & \lambda a_{i}+b_{0} \lambda^{0} \lambda x_{1 i t-1}+\ldots+b_{0} \lambda^{k} \lambda x_{1 i t-k}+\ldots+ \\
& q_{0} \lambda^{0} \lambda x_{p i t-1}+\ldots+q_{0} \lambda^{k} \lambda x_{p i t-k-1}+\lambda v_{i t-1}
\end{aligned}
$$

By subtracting Equation 3 from Equation 2 and ignoring the terms $b_{0} \lambda^{k+1} x_{1 i t-k-1}, \ldots$, $q_{0} \lambda^{k+1} x_{p i t-k-1}$, we eventually obtain the ARDL (Koyck lag formulation of the geo lag model):

$$
y_{i t}=a_{i}^{*}+b_{0} x_{1 i t}+c_{0} x_{2 i t}+\ldots+q_{0} x_{p i t}+\lambda y_{i t-1}+v_{i t}
$$

where $a_{i}^{*}=a_{i}(1-\lambda)$ and $a_{i}=a_{i}^{*} /(1-\lambda)$ and $v_{i t}=v_{i t}-\lambda v_{i t-1}$.

In the geometric lag model and its Koyck transformation (the ARDL), all explanatory variables $\left(x_{1 i t}, x_{2 i t}, \ldots, x_{p i t}\right)$ have a geometrically declining impact on the

\footnotetext{
${ }^{2}$ For efficient estimation of models for panel data see Ahn and Schmidt (1995) and Anderson and Hsiao (1982).
} 
dependent variable $y_{i t}$, in such a way that changes in the distant past have a more minor impact than changes in the more recent past (see Figure 1). In a multivariate dynamic regression model, all explanatory variables $\left(x_{1 i t}, x_{2 i t}, \ldots, x_{p i t}\right)$ have to impact on $y_{i t}$ in exactly the same geometric way, with the same $\lambda$. This pre-condition can become extremely restrictive. ${ }^{4}$

\section{[Figure 1 about here]}

In addition, there are many instances in which the assumption of a geometric lag itself will not be fulfilled. This will be true especially when reaction lags are present and when changes in the current and the preceding periods therefore have a lesser impact than changes in earlier periods. In such cases, a better option is a polynomial lag model, which allows us to estimate any lag structure that can be depicted by a polynomial of order $1,2, \ldots, p$.

A severe shortcoming of the ARDL is that the estimators will be inefficient and biased (even inconsistent) in the presence of autocorrelation of the disturbances (Kelejian and Oates, 1981). Additionally, the problem of neglecting $b_{0} \lambda^{k+1} x_{1 i t-k-1}$ can lead to huge errors (estimation mistakes) if $\lambda$ is relatively large and the maximum lag, $k$, is short. A short lag length might be a problem when working with annual data and less of a concern when working with daily or weekly data. This point will be elaborated and illustrated in the empirical results section (Section IV, Table 3).

\section{Estimation problems arising in an ARDL with longitudinal (pooled) data}

Dynamic panel data models usually use a small number of observations over time, whereas pooled data models are based on longer time spans (the number of

\footnotetext{
${ }^{3}$ Standard GMM utilises lagged variables as instruments. This leads to biased estimates in the presence of autocorrelation of the disturbances.

${ }^{4}$ In a bi-variate regression model, this assumption may not be so restrictive, but the assumption will also not always be fulfilled.
} 
observations over time is usually larger than the number of cross-sections, $T>N$ ). However, establishing a dynamic structure in the form of an ARDL with only a small number of observations over time (e.g., $T=2$ or $T=3$ ) is not a satisfying approach since building a dynamic model based on a very small number of observations over time can only capture the true dynamics "by chance". If possible, one should work with a longer time span (pooled data setting).

In settings with larger $T$, the time-series properties of the variables become relevant. All the time-series problems must be dealt with and the time-series properties of the variables must be scrutinised very carefully in order to avoid running spurious regressions. ${ }^{5}$ Scrutinisation of the series implies checking whether the series of the regression model have a memory, that is to say, whether $y_{i t}, x_{1 i t}, \ldots, x_{p i t}$ are determined by their past values. As is well known from the time-series literature, the unit root tests 6 check whether a series (see equations 5 through 7) is non-stationary, whether it has a unit root, with $\left|\rho_{i}\right| \geq 1$ in the $H_{0}$-hypothesis (Davidson and MacKinnon, 1993, Hamilton, 1994, and Hayashi, 2000). ${ }^{7}$

$$
\begin{aligned}
& y_{i t}=\rho_{y i} y_{i t-1}+u_{i t} \\
& x_{1 i t}=\rho_{x 1 i} x_{1 i t-1}+u_{i t} \\
& x_{p i t}=\rho_{x p i} x_{p i t-1}+u_{i t}
\end{aligned}
$$

\footnotetext{
${ }^{5}$ This problem was discussed extensively by Granger and Newbold (1974) and led to the development of stationarity tests (unit-root tests) such as the Augmented Dickey-Fuller test (1979), the Phillips-Perron test (1998), the Kwiatkowski, Phillips, Schmidt, and Shin test (KPSS, 1992), the GLS-detrended DickeyFuller test (Elliott, Rothenberg, and Stock, 1996), the Elliott, Rothenberg, and Stock Point Optimal test (ERS, 1996), and the $\mathrm{Ng}$ and Perron test (NP, 2001).

${ }^{6}$ In the last ten years, enormous progress has been made in the field of panel/pool unit root tests. There are two types of panel/pool unit root tests. One type assumes panel homogeneity (common unit root processes for all cross-sections). These tests were developed by Levin, Lin, and Chu (2002), Breitung (2000), and Hadri (1999). The second type of tests allows for panel heterogeneity. The Im-Pesaran-Shin test (IPS test, 2003), the Fisher-type tests using ADF, and the Phillips-Perron test (Maddala and Wu, 1999; Hadri (2000), Choi (2001), Hadri and Larsson (2005)) are based on individual unit roots or coefficients $\rho_{i}$ for each cross-section.

${ }^{7}$ For simplicity, neither constants nor trends are included in the equations.
} 
If the series in the regression model has a strong memory of the past, there is a high likelihood that the omitted variables, which are lumped together in the error term $v_{i t}$, will have a strong memory of the past, as well. They need not necessarily possess a unit root (be non-stationary with a $\rho$ close to one), but the probability that the error terms will be auto-correlated is high, i.e., $v_{i t}=\rho_{i} v_{i t-1}$, with $\rho_{i}$ being significantly different from zero.

Hujer et. al. (2005), Kim et al. (2003), Sevestre and Trognon (1996) and Keane and Runkle (1992) have studied the issue of serial correlation of the disturbances. To tackle serial correlation, Keane and Runkle (1992) and Kim et al. (2003) propose the forward-filtering 2SLS method (KR estimate). This method pretends serial correlation to be equal to $1\left(\rho_{i k}=1\right)$, which is a very rough estimate. Kim et al. (2003) refine the KR method. We, in contrast, estimate the extent of serial correlation in the sample (our $\left.\hat{\rho}_{i k}\right)^{8}$ and then transform the variables correspondingly (in soft or quasi-first differences) applying the FGLS technique. ${ }^{9}$

However, autocorrelation of the residuals is not the only problem. When a lagged endogenous variable appears on the right-hand side of a regression equation (as in Equation 4) and when the disturbances are autocorrelated, the lagged endogenous variable will automatically be correlated with the disturbance term and thus become endogenous. The endogeneity problem of the lagged dependent variable $\left(y_{i t-1}\right)$, which is caused by first-order AR correlation of the residuals due to non-stationarity of the series, can be effectively tackled by the Two-Stage Least Squares technique utilising 2SFGLS. Typical standard GMM procedures, in contrast, such as those summarised in

\footnotetext{
${ }^{8}$ In FGLS, the unknown serial correlation coefficient is estimated as described in Section II.

${ }^{9}$ In samples with sufficiently large $\mathrm{T}^{9}$ and errors that follow an AR process, ECM or Dynamic Ordinary Least Squares (DOLS) techniques can be applied, but in samples with shorter T, FGLS techniques are preferable.
} 
Baltagi (2005) cannot be applied in the presence of autocorrelation since the instruments (variables with two or more lags; both in levels or in differences) used for the lagged dependent variable will also be correlated with the error term through $v_{i t-1}$.

Moreover, cross-section correlation among the residuals is expected to be a very probable feature in pooled data sets. In this instance, it is advisable to build a system of equations (with one equation per cross-section) and estimate the system with the Seemingly Unrelated Regression (SUR) technique ${ }^{10}$. If the SUR-technique is combined with Two-Stage Least Squares (to control for endogeneity) it is called Three-Stage Least Squares (3SLS). If it is furthermore combined with FGLS (to control for autocorrelation), we will call it 3SFGLS. This technique, as well as non-standard GMM combined with SUR (to control for cross-section correlation), will be applied in Section IV.

\section{The model specification and estimation techniques}

From an applied economist's point of view, the objective of this paper is to analyse Chile's market share in the EU market on a sectoral level over the period from 1988 to 2002, applying the necessary panel/pooled time-series techniques. The ARDL model is built on six cross-sections (EU countries) and 15 annual observations for Chile's seven most important export sectors (fish, fruit, wine, ores, wood, wood pulp, and copper).

\section{The market share ARDL model}

Following Sutton (2004), there are two contradicting views on the development of market shares over time: the first goes back to Alfred Chandler and asserts that

\footnotetext{
${ }^{10}$ Building a system is only possible if the number of cross-sections is small.
} 
market shares are robust over time and that leadership tends to persist for a substantial time. The second view, propagated by Schumpeter, emphasises the transience of leadership positions. Schumpeter labels those leadership positions that arise from invention and innovation temporary monopolies. However, there is no benchmark for long or short leadership positions (2002 Japan Conference, 2005).

We will test the relevance of these hypotheses by means of panel/pooled unit root tests. If market shares turn out to be stationary $(\mathrm{I}(0))$, this will indicate that they are robust and persistent during the period from 1988 to 2002 . However, if they are instead non-stationary, then we will conclude that the Schumpeter hypothesis cannot be rejected by the data. Of course, our time period is too short to draw conclusions about whether the Schumpeter hypothesis is valid in the long run.

There are also two econometric approaches to modelling market shares: According to the first, market shares are basically purely stochastic, and according to the second, they are influenced by hard economic factors such as prices, marketing expenditures, the number and strength of competitors, etc. To model market shares, Sutton (2004) chooses a mix of the first and the second approaches (eclectic approach). Favouring the idea of building a stochastic model, he expands the model to include industry-specific features (e.g., a strategic representation of firms' competitive responses to market-share changes). However, it has to be kept in mind that strategic behaviour is very often intrinsically unobservable.

Cable (1997) models market shares according to the eclectic econometric approach and uses an autoregressive distributive lag model (ARDL). He selects a firstorder autoregressive model with a one-period lagged endogenous variable implying a temporary persistence of market shares. In his model prices and advertising shares ${ }^{11}$ are

\footnotetext{
11 Advertising is important when selling a differentiated product, but not when selling rather homogeneous products (as in our case study).
} 
the explanatory variables for the UK's national daily newspapers. Other authors also emphasise the importance of non-price factors as explanatory variables for the export market share (stemming from advertising and technological advantage (research and development)) when studying industrialised countries and the manufacturing sector (Hula, 1989; Das et al., 1993; Amable and Verspagen, 1995). ${ }^{12}$

We follow Cable's approach in terms of dynamic modelling, but not in terms of the determining variables. We stress the role played by observable and quantifiable factors, such as bilateral real effective exchange rates ${ }^{13}$. Thus we believe that exchange rates, cost differentials, tariffs, and subsidies are important hard factors explaining market shares over time. Accordingly, we build a dynamic econometric model in which price competitiveness (Chile's and its competitor's bilateral real effective exchange rate) is considered decisive for the competitive position (see Equation 8). Price competitiveness is considered a decisive determinant of Chile's market shares, since Chile's most successful exports are rather homogeneous products (fish, fruit, beverages, ores, copper, and wood and products thereof). Thus, our empirical model is of the following form:

$$
\begin{aligned}
l s h w_{i s t}= & a_{i s}+\beta_{0} \text { lreer }_{\text {ist }}+\gamma_{0} \text { lreer }^{*}{ }_{\text {ist }}+\lambda l s h w_{i s t-1}+v_{\text {ist }} \\
l s h w_{i s t}= & a_{i s}+\beta_{0} \text { lreer }_{i s t}+\beta_{0} \lambda^{k+1} \text { lreer }_{i s t-k-1}+ \\
& \gamma_{0} \text { lreer }_{i s t}^{*}+\gamma_{0} \lambda^{k+1} \text { lreer }^{*}{ }_{i s t-k-1}+\lambda l s h w_{i s t-1}+v_{i s t}
\end{aligned}
$$

Equation 8 is the simple ARDL and Equation 9 is the complete Koyck transformation, where $i=1,2, \ldots, 6$ represents the cross-sections: France (FRA), the Netherlands (NDL), Germany (DEU), Italy (ITA), Great Britain (GBR), and Spain (ESP); $t=1988$,

\footnotetext{
${ }^{12}$ We fully agree with the importance of non-price factors in the industry sectors.

${ }^{13}$ The bilateral real exchange rate captures the depreciation of the euro vis-á-vis the US dollar in the 1995 to 2001 period and the appreciation of the Chilean peso with respect to the US dollar in the period from
} 
$1989, \ldots, 2002$ are years (annual observations), $s=03,08,22,26,44,47$, and 74 are the sectors (according to the two-digit HS classification), lshwist stands for Chile's market share in EU country $i$ in sector $s$ at point $t$, lreer $_{\text {ist }}$ is Chile's real effective exchange rate, prevailing in EU country $i$ and in sector $s$, and lreer $^{*}{ }_{i s t}$ is Chile's competitor's $(*)$ real effective exchange rate, prevailing in country $i$ and in sector $s$. Since lreer and lreer* are in price quotation, we expect lreer to have a positive impact and lreer* to have a negative impact.

Market shares in a specific sector $(s)$ are computed as a ratio of Chile's sectoral exports ( $X$ in the numerator) and EU country i's imports from the world $M_{. i}=M_{\mathrm{EU} i}+$ $M_{\text {non-EUi }}$ (in the denominator). Due to unsubstantial trade volumes, we consider only Chile's market shares in France, the Netherlands, Germany, Italy, UK, and Spain. Market shares are computed for seven sectors at the two-digit HS levels, namely, fish (03), fruit (08), beverages (22), ores (26), wood (44), wood pulp (47), and copper (74). The data are from COMEXT and TradeCAN.

As to the peso-euro development, the peso appreciated in general terms against the euro from 1988 to 2002 so that Chile's price competitiveness was dampened. ${ }^{14}$ This effect was due to appreciation of the peso against the US dollar from 1993 to 1997 and depreciation of the euro (or of the DM, French franc, lira, etc.) in relation to the US dollar over the period from 1995 to 2001. However, this effect is captured in the bilateral real exchange rate and does not require the introduction of a dummy variable.

A detailed description of the data (including their calculation) can be found in the appendix of the working paper version of this paper or at http://www2.vwl.wiso.unigoettingen.de/iberoAppendix_AECON_08.pdf. The estimation period is from 1988 to 
2002. Thus, we obtain a maximum of six cross-sections and 15 years, resulting in a maximum of 90 observations per sector. The number of observations varies depending on the sector studied.

We estimate Equation 8 as a fixed-effect model allowing for cross-sectionspecific intercepts. This model could be applied in its unrestricted form by estimating cross-section-specific slope parameters for lreer $_{\text {ist }}$, lreer $*_{i s t,}$ and $l s h w_{i s t-1}\left(\beta_{0 i}, \gamma_{0 i}\right.$, and $\lambda_{i}$ ), but given our limited number of observations in each cross-section, we stick to common slope parameters in all countries.

As shown in Section II, Equations 8 and 9 are derived from the geometric lag model:

$$
\begin{array}{r}
l s h w_{i s t}=a_{i s}+\beta_{0} \lambda^{0} \text { lreer }_{\text {ist }}+\ldots+\beta_{0} \lambda^{k} \text { lreer }_{\text {ist }-k}+ \\
\gamma_{0} \lambda^{0} \text { lreer }^{*}{ }_{i s t}+\ldots+\gamma_{0} \lambda^{k} \text { lreer }^{*}{ }_{\text {ist }-1}+v_{i s t}
\end{array}
$$

As to the coefficients and the disturbance in this type of model, it is assumed that $0<\lambda<1$ and that $\lambda$ is the same for all regressors. Furthermore, it is assumed that $\beta_{\text {lag }}=\beta_{0} \lambda^{\text {lag }}, \gamma_{\text {lag }}=\gamma_{0} \lambda^{\text {lag }}$, and $v_{\text {ist }} \sim \mathrm{N}\left(0 ; \sigma_{v}^{2}\right)$. Note that Equation 10 assumes not only a geometric reaction of the market share $(l s h w)$ with respect to relative prices ( $\beta_{i}$ and $\gamma_{i}$ must follow a geometric lag) in all six importing countries $\mathrm{i}$ under investigation, but it assumes exactly the same geometric reaction (as measured by $\lambda_{i}$ ) of $l s h w_{i s t}$ with respect to changes of all the regressors (both lreer $_{\text {ist }}$ and lreer $_{\text {ist }}{ }^{*}$ ). In our case, as well as in many other studies using the ARDL, the above assumption cannot be justified by the data for all regressors. Also, the specific geometric reaction does not always apply to all countries under study. These issues would become even more

\footnotetext{
${ }^{14}$ Appreciation of the peso was less pronounced with respect to the British pound (GBP).
} 
crucial with an increasing number of cross-sections and with some more explanatory variables in the model (a model with, for example, 100 countries and five regressors).

Therefore, before applying our data to the ARDL, we examined the crosscorrelations between the dependent and the independent variables ${ }^{15}$ (12 per sector, 84 cross-correlations in total). With the help of cross-correlations, the dynamics of the model (the lag structure between dependent and independent variable) can be studied. The cross-correlations indicate that the geometric lag assumption is not fulfilled in a variety of cases and that the maximum lag length is between two and three years.

\section{Estimation techniques in the presence of non-stationary data}

a) Testing the time-series properties of the data

In the first step, we test the time-series properties of the data (all in natural logs). All series, i.e., market shares (lshw), Chile's real effective exchange rate (lreer) and Chile's competitors' real effective exchange rates (lreer*) for all country pairs are subjected to tests of non-stationarity (panel unit root tests). This procedure is applied to all seven sectors under investigation, neglecting the possible existence of structural breaks in the series because neither fundamental, abrupt changes in economic policy, nor any major exogenous shocks were detected in the period from 1988 to $2002 .^{16}$

In the statistical analysis we allow for different unit root processes in the panel, i.e., cross-section-specific (country-specific) unit roots. We apply the Im, Pesaran, and Shin (2003) panel unit root test to all series considering the possibility of individual unit roots of our panel data. We find that almost all variables (lshw, lreer, and lreer*) are

\footnotetext{
15 These cross-correlations show the reaction pattern between the dependent and the independent variables very clearly and should precede the building of any dynamic models. The 84 cross-correlations are available from the authors upon request.

${ }^{16}$ The economic policy of the Pinochet government was continued under the governments of Aylwin, Frei, and Lagos. Consequently, the time series display no sign of a significant structural shift.
} 
non-stationary, and integrated of order one, I(1) (results are not reported to save space). Of course, we have to be cautious in interpreting the results, since unit root tests generally tend to falsely accept the unit root null in small samples. Nevertheless, this result of non-stationarity is in line with our finding that in general the residual terms follow an $\mathrm{AR}(1)$ process (AR processes have a long memory ${ }^{17}$ ) and not an $\mathrm{MA}(1)$ process (MA processes have a short memory (Hujer, 2005)). Besides that, we can already conclude from the plots of the data (available at: http://www2.vwl.wiso.unigoettingen.de/ibero/Appendix_AECON_08.pdf) that the market shares exhibit nonstationary behaviour.

With respect to market shares, this finding supports Schumpeter's view that gains in market shares are temporary. Monopolistic positions have to be defended; otherwise they are lost quickly. This view seems to apply especially to the fish, fruit, beverages, ores, and copper sectors. Market shares appeared more stable in the wood sectors (44 and 47) (see http://www2.vwl.wiso.uni-goettingen.de/ibero/ Appendix_AECON_08.pdf), but are non-stationary according to the tests. This is in line with the results of Resende and Lima (2005), who found market share instability and market rivalry in the Brazilian industry utilising panel unit root tests, as well.

\section{b) The FGLS approach versus co-integration approaches}

When all variables are I(1), one could proceed with co-integration analysis and panel co-integration tests (Pedroni, 1999; Pedroni, 2004; Breitung and Pesaran, 2005). However, co-integration is a long-term concept that is not applicable to our rather short time span. Moreover, with fifteen annual observations, the power of panel co-

\footnotetext{
${ }^{17}$ Macroeconomic data usually show unit roots in the series and are therefore plausibly characterised by an autoregressive error process.
} 
integration tests would be extremely low. ${ }^{18}$ But co-integration analysis is not the only approach that deals with non-stationary series, and yields unbiased and efficient estimates in a dynamic model. ${ }^{19}$ FGLS is another possibility, as is known from time series analysis. Therefore, we exploit the special suitability of FGLS for estimating dynamic models with panel data (see Stock and Watson, 2003).

In a panel/pooled analysis setting, FGLS works in analogy to the time series setting. The idea remains the same: non-stationarity of the series in a regression equation is reflected in the autocorrelation $\rho$ of the residuals over time. Annual data usually shows first-order autocorrelation, and this is the case in our sample, as well. ${ }^{20}$ The FGLS method is applied in three steps. First, Equation 8 is estimated by SUR and the residuals $\hat{v}_{i t}$ are computed. Second, the order (first-order, second-order, or p-order) of autocorrelation $\hat{\rho}_{k}$ is estimated applying SUR and testing its significance ${ }^{21}$ in Equation 11:

$$
\hat{v}_{i s t}=\sum_{k=1}^{K} \rho_{i s k} \hat{v}_{i s t-k}+e_{i s t},
$$

where $e_{i s t} \sim \mathrm{N}\left(0 ; \sigma_{e i}^{2}\right)$ and $k=1,2, \ldots, K$ is the number of lags. Third, if only first-order autocorrelation is present (as in our case), the variables of Equation 8 are transformed into

$$
\begin{aligned}
& l s h w z_{i s t}=l s h w_{i s t}-\hat{\rho} l s h w_{i s t-1}, \\
& \text { lreerz }_{i s t}=\text { lreer }_{i s t}-\hat{\rho} \text { lreer }_{i s t-1},
\end{aligned}
$$

\footnotetext{
${ }^{18}$ We have estimated the market share dynamics with an ECM based on an ARDL. However, using this procedure, we could explain much less of the variation of market shares, i.e., our $\mathrm{R}^{2}$ (adjusted) were much smaller.

${ }^{19}$ Rao (2007) reviews three alternative approaches, viz., general to specific, vector autoregressions, and vector-error correction models, to estimate short and long-run relationships.

${ }^{20} \rho$ is usually well below 1 ; first differencing thus is a very imprecise (ineffective) method to remove stationarity.
} 


$$
\begin{aligned}
& \operatorname{lreerz}^{*}{ }_{i s t}=\operatorname{lreer}^{*}{ }_{i s t}-\hat{\rho} \text { lreer }_{i s t-1}, \\
& l s h w z_{i s t-1}=l s h w_{i s t-1}-\hat{\rho} l s h w_{i s t-2}, \text { and } \\
& \varepsilon_{i s t}=\hat{v}_{i s t}-\hat{\rho} \hat{v}_{i s t-1},
\end{aligned}
$$

thus generating variables in soft or quasi-first differences. Equation 8 is then estimated on the basis of the transformed variables (see Stock and Watson, 2003):

$$
l s h w z_{i s t}=a_{i s}(1-\hat{\rho})+\beta_{0} \text { lreerz }_{i s t}+\gamma_{0} \text { lreerz }^{*}{ }_{i s t}+\lambda l s h w z_{i s t-1}+\varepsilon_{i s t} .
$$

\section{Estimating the market share ARDL}

For each sector, separate panel ARDLs (applying Equation 8) are run over the time period 1988 to 2002, with the EU countries acting as cross-sections in the panel analysis. To control for autocorrelation, FGLS is combined with either 3SLS based on a system of equations or a non-standard GMM-type routine. Our system contains six equations, one for each cross-section/destination market/EU market ${ }^{22}$. Possible crossequation/cross-section correlation of the error terms is controlled for by estimating the system of equations by means of SUR. Cross-section correlation can result from for example inter-related shifts in preferences (a shift in favour of biologically produced fish or fruit or in favour of higher quality wine, wood, copper, and ores etc.) that happens in all or some of the six EU markets under study. The presence of autocorrelation leads us to use instruments from outside the system, instead of using lagged values of the endogenous variables as instruments (which is the standard

\footnotetext{
${ }^{21}$ In our data first-order autocorrelation of the type $\hat{v}_{i t}=\hat{\rho}_{i 1} \hat{v}_{i t-1}$ turns out to be present and dominant. $\hat{\rho}_{i 1}$ expresses first-order autocorrelation, henceforth to be called $\hat{\rho}$.

${ }^{22}$ The system/SUR approach is recommended when the number of $N$ is small (six in our case) and $T$ is large (15 in our case).
} 
technique). These instruments are utilised both in the 3SLS (2SLS-SUR) routine and in the non-standard GMM routine.

\section{The 3SLS approach}

The choice of instruments is crucial in order to obtain consistent estimates in any model, including in the market share model. We used an indicator of production capacity in real terms as an instrument for lagged market share $\left(l s h w_{i s t-1}\right)$, the difference in PPP-income between Chile and the importing country as an instrument for lreer $_{\text {ist }}$, and the competitor's real exchange rate in a transformation that is generally used in polynomial lag models as an instrument for lreer $_{\text {ist }}$. Table 1 summarises the impact of price competitiveness on market shares estimated by Three-Stage Feasible Generalised Least Squares (3-SFGLS).

\section{[Table 1 about here]}

Under the assumption that the data follow an ARDL model, we find a significant positive impact of increased Chilean price competition on market shares in the fish (03), fruit (08), and ores (26) sectors, but no significant negative impact of foreign price competition on market shares in six out of seven sectors under study. As to beverages (22) which mainly consist of wine exports, we find a negative impact of competitive (low) Chilean prices and a positive impact of low foreign prices on market shares. FAO statistics (FAO Production Yearbook, 2003; FAO Trade Yearbook, 2003) show that Chile increased its wine production in the period 1978 to 2002. Such a production increase, which is usually achieved by intensified irrigation and fertilisation, leads to inferior wines at lower prices. Our regression results indicate that consumers in the EU associate low price with low quality and therefore reduce demand. Therefore, we tend to 
conclude that quality considerations dominate price considerations in the beverages sector. Adjustment to the long-run equilibrium was significant in the beverages (22), ores (26), wood (44), wood pulp (47), and copper (74) sectors, whereas no significant adjustment took place in the fish (03) and fruit (08) sectors.

\section{The non-standard GMM-type approach}

In the absence of serially correlated error terms, the standard (classic) GMM approach does have a comparative advantage over 3SLS in controlling endogeneity. Control of endogeneity is 100 percent due to specific model restrictions and therefore leads to a gain in unbiasedness. However, efficiency is lost by creating a tremendous amount of moment conditions that have to be taken into account. In our case, we get 210 moment conditions, i.e., 210 restrictions $^{23}$, which fact highlights the computational burden of this approach (Schmidt et al., 1992).

However, in the presence of autocorrelation of the disturbances (as in our case study), the standard GMM approach, which uses lagged variables as instruments for endogenous regressors, must be avoided, since this strategy of creating instruments for endogenous variables fails due to autocorrelated errors (Durlauf et al., 2004). This shortcoming also applies to the Arellano-Bond (1991) estimator which is based on running the regression in first differences.

In order to solve the problem of endogeneity, we estimate the dynamic model by non-standard GMM (for GMM see: Holtz-Eakin et al., 1988; Arellano and Bond, 1991; Caselli, Esquivel and Lefort, 1996; Durlauf et al., 2004) without utilising lagged variables as instruments. Instead, we take exactly the same ones as in the 3SLS routine

\footnotetext{
${ }^{23}$ The number of restrictions is $T(T-1) K / 2$.
} 
described in the previous section: the difference in PPP income between Chile and the importing country, an indicator of production capacity in real terms, and the real exchange rate in a transformation that is generally used in polynomial lag models.

\section{[Table 2 about here]}

Assuming for the moment that the underlying preconditions of the autoregressive lag model are fulfilled, we can conclude from Table 2 that there is a positive relationship between an increase in Chilean price competitiveness and market share in the fruit sector (08) and a negative relationship between low Chilean wine prices (sector 22) and high Chilean copper prices (sector 74) and their respective market shares. Foreign relative prices have a significant impact in the fish (03), beverages (22), and ores (26) sectors. The role of prices in the wood (44) and wood pulp (47) sectors might be severely impeded by illegal logging and illegal imports of wood products. Illegal logging distorted official trade flows not only of all timber products (roundwood, sawn wood, veneer, plywood, boards, semi-finished and finished products, and furniture), but also of pulp, paper, printed products, and cellulose. ${ }^{24}$ This latter statement applies also to the interpretation of the 3SLS estimation.

\section{Error analysis}

The results concerning the slope coefficients of the price competitiveness variables must be taken with caution if the actual lag length of market-share dynamics is small. In our case study, the maximum lag length was about two to three years

\footnotetext{
${ }^{24}$ Illegal logging is estimated to comprise up to 50 percent of all logging activity in the key countries of Eastern Europe and Russia, up to 94 percent in the key Asian countries, up to 80 percent in the key African countries, and up to 80 percent in the key Latin American countries (WWF, 2005; FERN, 2004).
} 
according to the cross-correlations. When transforming Equation 10 into the simple ARDL (Equation 8) (which must be considered an incomplete Koyck transformation), an error occurs by suppressing the terms $\beta_{0} \lambda^{k+1}$ lreer $_{i s t-k-1}$ and $\gamma_{0} \lambda^{k+1}$ lreer $^{*}{ }_{i s t-k-1}$. The shorter the actual lag $\left(k_{\max }\right)$ and the closer $\lambda$ (the adjustment parameter) is to 1 , the larger this error is. The extent of the error becomes intuitively clear by treating Equation 9 as the true ARDL and considering it as the complete Koyck transformation.

The actual error computation is very straightforward. If the maximum actual lag is $\mathrm{k}$, then the error occurs by dropping the terms $\beta_{0} \lambda^{k+1}$ lreer $_{\text {ist }-k-1}$ and $\gamma_{0} \lambda^{k+1}$ lreer $*_{i s t-k-1}$ is $\lambda^{k+1}$. This implies that a maximum lag length of one (two) will lead to an error of $\lambda^{2}\left(\lambda^{3}\right)$. When working with annual data, a specification with one or two- year (maximum) lags can be very common, such that the danger of committing an error is relatively high.

\section{[Table 3 about here]}

We can draw several conclusions from the error analysis in Table 3:

(1) The data do not fit the autoregressive lag model in the fruit sector (3SLS and GMM estimation) or in the fish sector (3SLS estimation). The $\lambda s$ there carry the wrong sign and are insignificant since the ARDL requires significant positive $\lambda s$ that lie in an interval $] 0 ; 1[$.

(2) The data can be explained by an ARDL in the rest of the sectors by and large since the $\lambda s$ lie in an interval $] 0 ; 1[$. However, since we work with annual data where the maximum lag length is usually short $\left(k_{\max }=2\right.$ is very realistic according to the cross-correlations), large errors will result in the beverages, ores, and copper sectors; $\lambda$ is relatively large and the omission of the terms 
$\beta_{0} \lambda^{k+1}$ lreer and $\gamma_{0} \lambda^{k+1}$ lreer* will therefore result in a large error. For example, for $\lambda=0.80$, the error is 64 percent if $k_{\max }$ is 1 , and 51 percent if $k_{\max }$ is 2 . That is, 64 percent or 51 percent of the impact of copper prices on the market share in copper is neglected. Large errors also occur in the beverages, ores, and wood sectors given that $\lambda$ is relatively large there.

(3) Note that the errors are even larger than computed when we have reason to assume that the geometric lag structure does not apply in all instances. Computation of errors in this case would require knowledge of the true model.

\section{Comparison of the 3SLS and the non-standard GMM results}

On the one hand, we have found that the ARDL estimations in Section IV have very respectable adjusted $\mathrm{R}^{2}$ measures and Durbin-Watson (DW) statistics around $2 .{ }^{25}$ On the other hand, the standard errors of the regressions are relatively high. Moreover, the error analysis makes clear that the simple dynamic specification in the form of an ARDL suffers from some drawbacks. The autoregressive lag specification does not seem to apply in the fish or the fruit sectors. Statements in the beverages, ores, wood, and copper sectors are subject to relatively large errors due to neglecting the term $\lambda^{k+1}$, the impact of changes in prices, and protection ${ }^{26}$ in the autoregressive transformation.

The estimation results of 3SLS and non-standard GMM differ widely. This result is puzzling since fixed effects and exactly the same instrumental variables are utilised in both estimation procedures. However, 3SLS and non-standard GMM differ in the number of restrictions applied. 3SLS basically works under the condition of

\footnotetext{
${ }^{25}$ Even though the DW statistic must be adjusted in the presence of a lagged endogenous variable, the DW statistic is still able to roughly indicate problems of autocorrelation and misspecification. A better measure of autocorrelation is probably Bhargava's et al. (1981) DW statistic.
} 
minimising the squared residuals of Equation 8 with instruments replacing the righthand-side variables. GMM estimation, in contrast, is built around a multitude of moment conditions, some of which will be relevant and others irrelevant. The GMM routine does not involve a search for relevant moment conditions, and thus some irrelevant moment conditions can become binding (see Ziliak, 1997). Therefore, in our view, 3SLS is superior to GMM.

Moreover, it must be noted that the estimation results of both 3SLS and nonstandard GMM do not fulfill our expectations as far as signs (especially in GMM) and significance are concerned. This certainly has to do with violated model assumptions but also with the simplicity of the model (we do not control for quality). Therefore, the empirical results should not be overemphasised, nor should they be utilised for further analysis.

\section{Conclusions}

Assuming that the underlying geometric lag specification can be applied to the data, the ARDL specification allows us to draw correct inferences about the short, medium, and long run. The ARDL specification can be combined with the FGLS and the SUR technique and is therefore able to deal with several estimation problems resulting from autocorrelation, heteroscedasticity and cross-sectional correlation of the disturbances. Applied to a system of equations, this technique transforms the variables in the regression equation by working with soft differences in the variables and by weighting the regressor matrix with a weight matrix that can control for heteroscedasticity of the variance of the residuals (White method) and for cross-sectional correlation of the

\footnotetext{
${ }^{26}$ All our prices contain sector-specific protection whenever relevant.
} 
disturbances (SUR method). The endogeneity problem is solved with instrumental variables IV in either a 3SLS or a non-standard GMM-type routine. Unlagged exogenous variables are utilised to control for the endogeneity problem and to obtain unbiased estimates. Furthermore, the 3SFGLS and the non-standard GMM-type technique are able to produce efficient and consistent estimates if ARDL is the true model.

Violation of the geometric lag assumption is to be expected in particular when working with heterogenous panel data and with multivariate regression models, and will result in inconsistent estimators. In this case, a polynomial lag model could be the model of choice if there is not excessive cross-sectional heterogeneity. Estimations in the framework of panel error correction models and panel DOLS could be highly advisable even though these models require much longer time spans to allow for meaningful panel unit root and panel co-integration tests. Further research is needed on this topic.

Our study has demonstrated that the ARDL model must be applied with caution for several reasons. First, the geometric lag assumption was not supported overall by the cross-correlations between dependent and independent variables. Second, a maximum lag length of two to three years (also visible in the cross-correlations) can result in substantial estimation errors. Third, non-stationarity of the series leads in general to autocorrelation of the residuals. It renders the utilisation of lagged instruments in a standard GMM framework obsolete and requires a search for new instruments, which instruments, however, may not be applicable in all cases. 


\section{Acknowledgement}

We are grateful to Stephan Klasen and an anonymous referee for excellent suggestions that considerably improved this paper. 


\section{References}

Ahn, S. and Schmidt,P. (1995) Efficient estimation of models for dynamic panel data, Journal of Econometrics 68: 5-27.

Amable, B. and Verspagen, B. (1995) The role of technology in market shares dynamics, Applied Economics 27: 197-204.

Anderson, T.W. and Hsiao, C. (1982) Formulation and estimation of dynamic models using panel data, Journal of Econometrics 18: 47-82.

Arellano, M. (1989) A note on the Anderson-Hsiao estimator for panel data, Economic Letters 31: 337-341.

Arellano, M. and Bond, S. (1991) Some tests of specification for panel data: Monte Carlo evidence and an application to employment equations, Review of Economic Studies 58: 277-297.

Balestra, P. and Nerlove, M. (1966) Pooling cross-section and time-series data in the estimation of a dynamic model: the demand for natural gas, Econometrica 34: 585612.

Baltagi, B.H. and Levin, D. (1986) Estimating dynamic demand for cigarettes using panel data: the effects of bootlegging, taxation, and advertising reconsidered, Review of Economics and Statistics 68: 148-155.

Baltagi, B.H. (2005) Econometric Analysis of Panel data, Third Edition, Colchester: John Wiley \& Sons, Ltd.

Bhargava, A. (1981) Serial correlation and the fixed effects model, Working Paper 33, London School of Economics and Political Science, International Centre for Economics and Related Disciplines. 
Blundell, R., Bond, S., Devereux, M. and Schiantarelli, F. (1992) Investment and Tobin's q: evidence from company panel data, Journal of Econometrics 51: 233257.

Blundell, R. and Bond, S. (1998) Initial conditions and moment restrictions in dynamic panel data models, Journal of Econometrics 87: 115-143.

Breitung, J. (2000) The local power of some unit root tests for panel data, in B. Baltagi (ed.), Advances in Econometrics, Vol. 15: Nonstationary Panels, Panel Cointegration, and Dynamic Panels, Amsterdam: JAI Press: 161-178.

Breitung, J. and Pesaran, H. (2005) Unit Roots and cointegration in panels, http://www.econ.cam.ac.uk/dae/repec/cam/pdf/cwpe0535.pdf (November 4, 2005).

Cable, J.R. (1997) Market share behavior and mobility: an analysis and time-series application, The Review of Economics and Statistics 79: 136-141.

Caselli, F. , Esquivel, G. and Lefort, F. (1996) Reopening the convergence debate: a new look at cross-country growth empirics, Journal of Economic Growth 3: 363389.

Choi, I. (2001) Unit root tests for panel data, Journal of International Money and Finance 20: 249-272.

Das, B.J., Chappell, W.F. and Shughartii, W.F. (1993) Advertising, competition and market share instability, Applied Economics 25: 1409-1412.

Davidson, R. and MacKinnon, J.G. (1993) Estimation and Inference in Econometrics, Oxford: Oxford University Press.

Dickey, D. A. and Fuller, W. A. (1979) Distribution of the estimators for autoregressive time series with a unit root, Journal of the American Statistical Association 74: $427-$ 431. 
Durlauf, S., Johnson, P. and Temple, J. (2004) Growth econometrics, Social Systems $\begin{array}{lllll}\text { Research } \quad \text { Institute, } & \text { SSRI }\end{array}$ http://www.ssc.wisc.edu/econ/archive/wp2004-18.pdf (February 6, 2006).

Elliott, G., Rothenberg, T. and Stock, J.H. (1996) Efficient tests for an autoregressive unit root, Econometrica 64: 813-836.

European Commission (2003), Intra- and extra-EU trade, Annual data, Combined Nomenclature, Supplement 2, EUROSTAT, CD ROM of COMEXT trade database. EU Commission (2005) The EU relations with Chile, http://europa.eu.int/comm/external_relations/chile/intro/ (November 24, 2005).

EViews 5: User's Guide (2004), Quantitative Micro Software, LLC, Irvine, CA.

FAO Production Yearbook (2003) Food and Agricultural Organization of the United Nations, Rome, Vol. 57.

FAO Trade Yearbook (2003) Food and Agricultural Organization of the United Nations, Rome, Vol. 57.

FERN, Greenpeace, WWF 2004:

http://www.panda.org/news_facts/newsroom/news.cfm?uNewsID=17214 (July 28, 2005).

Granger, C. and Newbold, P. (1974) Spurious regressions in econometrics, Journal of Econometrics 2: 111-120.

Greene, W.H. (2000) Econometric Analysis, London: Prentice Hall International (UK) Limited.

Hadri, K. (1999) Testing the null hypothesis of stationarity against the alternative of a unit root in panel data with serially correlated errors, The Econometrics Journal 3: $148-161$. 
Hadri, K. (2000) Testing for stationarity in heterogeneous panel data, Econometric Journal 3: 148-161.

Hadri, K. and Larsson, R. (2005) Testing for stationarity in heterogeneous panel data where the time dimension is finite, The Econometrics Journal 8: 55-69.

Hamilton, J.D. (1994) Time Series Analysis, Princeton, NJ: Princeton University Press.

Hayashi, F. (2000) Econometrics, Princeton, NJ: Princeton University Press.

Holtz-Eakin D., W. Newey and H. Rosen (1988) Estimating vector autoregressions with panel data, Econometrica 56: 1371-1395.

Hujer, R., Rodrigues, P. and Zeiss, C. (2005) Serial correlation in dynamic panel data models with weakly exogenous regressors and fixed effects, Working Paper, March 9, 2005, J.W. Goethe-University, Frankfurt, Germany.

Hula, D.G. (1989) Intangible capital, market share and corporate strategy, Applied Economics 21: 1535-1547.

Im, K., M. Pesaran and Y. Shin (2003) Testing for unit roots in heterogeneous panels, Journal of Econometrics 115: 53-74.

Islam, N. (1995) Growth empirics: a panel data approach, Quarterly Journal of Economics 110, 1127-1170.

2002 Japan Conference: A Summary of the Papers, NBER Website; http://www.nber.org/2002japanconf/sutton.html (July 29, 2005).

Keane, M. and Runkle, D. (1992) On the estimation of panel data models with serial correlation when instruments are not strictly exogenous, Journal of Business and Economic Statistics 10: 1-9.

Kelejian, H.H. and Oates, W.E. (1981) Introduction to Econometrics. Principles and Applications, New York: Harper \& Row Publishers. 
Kim, M.K., Cho, G.D. and Koo, W.W. (2003) Determining bilateral trade patterns using a dynamic gravity equation, Agribusiness \& Applied Economic Report No. 525, Center for Agricultural Policy and Trade Studies. North Dakota State University. http://www.ag.ndsu.nodak.edu/capts/documents/NovemberNewsletter2003-2-404.pdf (March 3, 2006).

Koyck, L.M. (1954) Distributed Lags and Investment Analysis, Amsterdam: North Holland.

Levin, A., Lin, C.F., and Chu, C. (2002) Unit root tests in panel data: asymptotic and finite sample properties, Journal of Econometrics 108: 1-24.

Maddala, G.S. and Wu, S. (1999) A comparative study of unit root tests with panel data and a new simple test, Oxford Bulletin of Economics and Statistics 61: 631-652.

Ng S. and Perron, P. (2001) Lag length selection and the construction of unit root tests with good size and power, Econometrica 69: 1519-1554.

Phillips, P. and Perron, P. (1988) Testing for a unit root in time series regression, Biometrika 75: 335-346.

OECD (1997) The Uruguay Round Agreement on Agriculture and Processed Agricultural Products, OECD Publications, Paris.

Pedroni, P. (1999) Critical values for cointegration tests in heterogeneous panels with multiple regressors, Oxford Bulletin of Economics and Statistics 61 Suppl.: 653670.

Pedroni, P. (2004) Panel cointegration: asymptotic and finite sample properties of pooled time series tests with an application to the PPP hypothesis, Econometric Theory 20: 597-625.

Rao, B.B. (2007) Estimating short and long-run relationships: a guide for the applied economist, Applied Economics 39: 1613-1625. 
Resende, M. and Lima, M.A.M. (2005) Market share instability in Brazilian industry: a dynamic panel data analysis, Applied Economics 37: 713-718.

Schmidt, P., Ahn, S.C. and Wyhowski, D. (1992) Comment, Journal of Business and Economic Statistics 10: 10-14.

Sevestre, P. and Trognon, A. (1996) Dynamic Linear Models, in The Econometrics of Panel Data. A Handbook of the Theory with Applications, edited by L. Mátyás and Sevestre, P. 120-144, Dordrecht: Kluwer Academic Publishers, $2^{\text {nd }}$ ed.

Stock, J. (1994) Unit roots, structural breaks, and trends, Chap. 46 in Handbook of Econometrics, Vol. IV, edited by R. Engle and D. McFadden, Amsterdam: Elsevier. Stock, J.H. and M.W. Watson (2003) Introduction to Econometrics, Boston [...]: Addison Wesley.

Sutton, J. (2004) Market share dynamics and the 'Persistence of Leadership' Debate. The Economics of Industry Group/Suntory and Toyota International Centres for Economics and Related Disciplines, London School of Economics, 37.

World Bank (2002) TradeCAN (Competitiveness Analysis of Nations) 2002 CD-ROM, Washington, D.C.

World Bank (2005) World Development Indicators, Data on CD ROM, Washington, D.C.

WTO Trade Policy Review, European Union (1995, 1997, 2000), World Trade Organisation, Geneva.

WWF (World Wildlife Fund): EU imports of wood-based products 2002 (2005): http://www.panda.org/about_wwf/wherewework/europe/problems/illegal_logging/ (April 29, 2005) 
Ziliak, J. (1997) Efficient estimation with panel data when instruments are predetermined: an empirical comparison of moment-condition estimators, Journal of Business and Economic Statistics 15: 419-431.

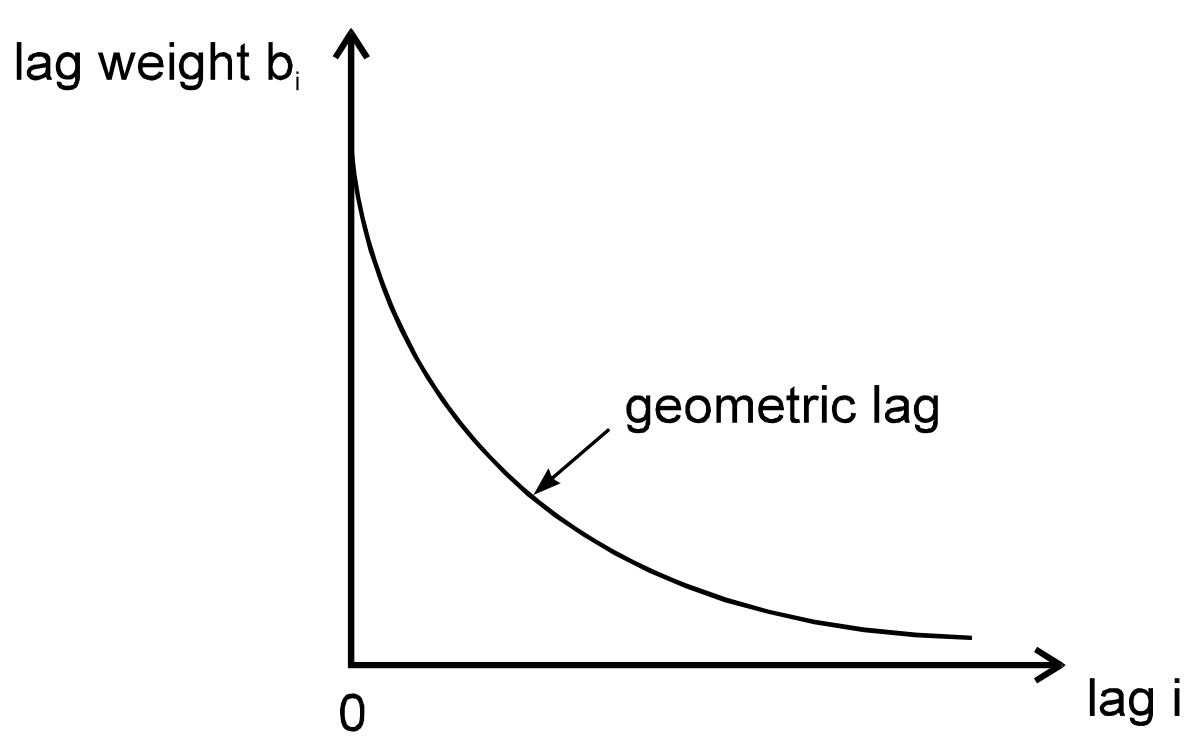

Notes: This reaction pattern must apply to all regressors $\left(\mathrm{x}_{1}, \mathrm{x}_{2}, \mathrm{x}_{3}, \ldots, \mathrm{x}_{\mathrm{p}}\right)$ and at all levels (crosssections $i) ! \lambda$ is assumed to be the same for all regressors. 
Table 1. Results for the ARDL market-share model estimated by 3SFGLS (with fixed effects)

\begin{tabular}{|c|c|c|c|c|c|c|c|}
\hline \multirow[t]{2}{*}{ Sector results } & \multicolumn{4}{|c|}{$\begin{array}{c}\text { Regression coefficients } \\
\text { Equation } 8\end{array}$} & \multicolumn{3}{|c|}{ Goodness of fit measure } \\
\hline & $\begin{array}{c}\text { lreer } \\
\beta_{0}\end{array}$ & $\begin{array}{c}\text { lreer* } \\
\gamma_{0}\end{array}$ & $\begin{array}{l}\text { Adjustm. } \\
\text { coeff. }(\lambda)\end{array}$ & AR-term & $\begin{array}{l}\text { (weighted) } \\
\mathrm{R}^{2} \text { adjusted }^{1}\end{array}$ & SE & DW \\
\hline 03 short run & $\begin{array}{c}0.82 * * \\
(0.02)\end{array}$ & $\begin{array}{l}-0.72 \\
(0.19)\end{array}$ & $\begin{array}{l}-0.19 \\
(0.20)\end{array}$ & $\begin{array}{c}0.68 * * * \\
(0.00)\end{array}$ & 0.97 & 1.02 & 2.15 \\
\hline 08 short run & $\begin{array}{l}1.82 * * \\
(0.02)\end{array}$ & $\begin{array}{l}-0.14 \\
(0.85)\end{array}$ & $\begin{array}{l}-0.07 \\
(0.70)\end{array}$ & $\begin{array}{c}0.69 * * * \\
(0.00)\end{array}$ & 0.99 & 1.05 & 1.99 \\
\hline 22 short run & $\begin{array}{c}-2.09 * * * \\
(0.01)\end{array}$ & $\begin{array}{c}2.01 * * * \\
(0.01)\end{array}$ & $\begin{array}{c}0.62 * * * \\
(0.00)\end{array}$ & $\begin{array}{l}-0.08 \\
(0.64)\end{array}$ & 0.98 & 1.05 & 2.04 \\
\hline 22 long run & $-5.50 * * *$ & $5.29 * * *$ & & & & & \\
\hline 26 short run & $\begin{array}{c}1.83^{* * *} \\
(0.00)\end{array}$ & $\begin{array}{c}0.06 \\
(0.42)\end{array}$ & $\begin{array}{c}0.70 * * * \\
(0.00)\end{array}$ & $\begin{array}{l}-0.29 * \\
(0.07)\end{array}$ & 0.96 & 1.02 & 2.06 \\
\hline 26 long run & $6.10 * * *$ & 0.20 & & & & & \\
\hline 44 short run & $\begin{array}{c}0.35 \\
(0.76)\end{array}$ & $\begin{array}{l}-2.35 \\
(0.13)\end{array}$ & $\begin{array}{c}0.46^{* * *} \\
(0.00)\end{array}$ & $\begin{array}{c}0.60 * * * \\
(0.00)\end{array}$ & 0.94 & 1.06 & 2.36 \\
\hline 44 long run & 0.65 & -4.37 & & & & & \\
\hline 47 short run & $\begin{array}{c}-1.20 * * * \\
(0.00)\end{array}$ & $\begin{array}{l}-0.27 \\
(0.42)\end{array}$ & $\begin{array}{c}0.37 * * * \\
(0.00)\end{array}$ & $\begin{array}{c}0.01 \\
(0.91)\end{array}$ & 0.99 & 1.07 & 1.87 \\
\hline 47 long run & $-1.90 * * *$ & -0.43 & & & & & \\
\hline 74 short run & $\begin{array}{c}-0.45 * * * \\
(0.00)\end{array}$ & & $\begin{array}{c}0.80 * * * \\
(0.00)\end{array}$ & $\begin{array}{l}-0.07 \\
(0.66)\end{array}$ & 0.99 & 1.04 & 2.16 \\
\hline 74 long run & $-2.25 * * *$ & & & & & & \\
\hline
\end{tabular}

Notes: p-values in brackets. $*, * *, * * *$ denote significance at the 10,5 , and 1-percent level, respectively. The estimated values of the fixed effects are not reported. ${ }^{1}$ In $3 \mathrm{SLS}$ the adjusted $\mathrm{R}^{2}$ is negative at times. It is unclear how the goodness of fit measures of the different cross-sections are to be weighted in order to derive an overall goodness-of-fit measure. Therefore, the figures listed should only signal the trend. 
Table 2. Results for the ARDL market-share model estimated by non-standard panel GMM (with fixed effects)

\begin{tabular}{|c|c|c|c|c|c|c|c|}
\hline \multirow[t]{2}{*}{ Sector results } & \multicolumn{4}{|c|}{$\begin{array}{c}\text { Regression coefficients } \\
\text { Equation } 8\end{array}$} & \multicolumn{3}{|c|}{ Goodness-of-fit measures } \\
\hline & $\begin{array}{l}\text { lreer } \\
\beta_{0}\end{array}$ & $\begin{array}{c}\text { lreer* } \\
\gamma_{0}\end{array}$ & $\begin{array}{l}\text { Adjustm. } \\
\text { coeff. }(\lambda)\end{array}$ & AR-term & $\begin{array}{l}\text { (weighted) } \\
\mathrm{R}^{2} \text { adjusted }\end{array}$ & SE & DW \\
\hline 03 short run & $\begin{array}{l}-0.20 \\
(0.24)\end{array}$ & $\begin{array}{c}-0.78^{* * *} \\
(0.00)\end{array}$ & $\begin{array}{c}0.64 * * * \\
(0.00)\end{array}$ & $\begin{array}{c}-0.24 * * \\
(0.02)\end{array}$ & 0.98 & 1.04 & 2.11 \\
\hline 03 long run & -0.55 & $-2.17 * * *$ & & & & & \\
\hline 08 short run & $\begin{array}{l}2.29 * \\
(0.07)\end{array}$ & $\begin{array}{l}-0.15 \\
(0.90)\end{array}$ & $\begin{array}{l}-0.15 \\
(0.42)\end{array}$ & $\begin{array}{c}0.69^{* * *} \\
(0.00)\end{array}$ & 0.99 & 1.10 & 1.98 \\
\hline 22 short run & $\begin{array}{c}-2.53 * * * \\
(0.00)\end{array}$ & $\begin{array}{c}2.29 * * * \\
(0.00)\end{array}$ & $\begin{array}{c}0.58 * * * \\
(0.00)\end{array}$ & $\begin{array}{l}-0.13 \\
(0.41)\end{array}$ & 0.98 & 1.06 & 2.08 \\
\hline 22 long run & $-6.02 * * *$ & $5.45 * * *$ & & & & & \\
\hline 26 short run & $\begin{array}{l}0.12 \\
(0.69)\end{array}$ & $\begin{array}{c}-0.28 * * * \\
(0.01)\end{array}$ & $\begin{array}{c}0.89 * * * \\
(0.00)\end{array}$ & $\begin{array}{c}-0.21 * * * \\
(0.05)\end{array}$ & 0.87 & 1.09 & 2.05 \\
\hline 26 long run & 1.09 & $-2.54 * * *$ & & & & & \\
\hline 44 short run & $\begin{array}{c}-1.22 * * \\
(0.04)\end{array}$ & $\begin{array}{l}-0.98 \\
(0.14)\end{array}$ & $\begin{array}{c}0.74 * * * \\
(0.00)\end{array}$ & $\begin{array}{c}-0.37 * * * \\
(0.00)\end{array}$ & 0.82 & 1.06 & 2.26 \\
\hline 44 long run & $-4.69 * *$ & -3.77 & & & & & \\
\hline 47 short run & $\begin{array}{c}-1.07 * * \\
(0.05)\end{array}$ & $\begin{array}{l}-0.31 \\
(0.52)\end{array}$ & $\begin{array}{c}0.40 * * * \\
(0.00)\end{array}$ & $\begin{array}{l}-0.05 \\
(0.80)\end{array}$ & 0.74 & 0.26 & 1.87 \\
\hline 47 long run & $-1.78 * *$ & -0.52 & & & & & \\
\hline 74 short run & $\begin{array}{c}-1.45 * * \\
(0.02)\end{array}$ & -------- & $\begin{array}{c}0.37 * * * \\
(0.03)\end{array}$ & $\begin{array}{c}0.49 * * * \\
(0.00)\end{array}$ & 0.99 & 1.18 & 2.01 \\
\hline 74 long run & -2.30 & & & & & & \\
\hline
\end{tabular}

Note: p-values in brackets. $*, * *, * * *$ denote significance at the 10,5 , and 1-percent level, respectively.

${ }^{1}$ The estimated values of the fixed effects are not reported. 
Table 3. Error analysis in the 3SLS and the non-standard GMM framework

\begin{tabular}{|c|c|c|c|c|c|c|}
\hline \multirow[t]{2}{*}{ Sector } & \multicolumn{3}{|c|}{ 3SLS framework } & \multicolumn{3}{|c|}{ Non-standard GMM framework } \\
\hline & 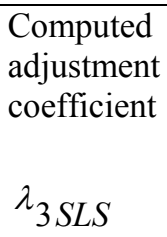 & $\begin{array}{c}\text { Error if } \\
\mathrm{k}_{\max }=1: \\
2 \\
\lambda_{3 S L S}\end{array}$ & $\begin{array}{l}\text { Error if } \\
\mathrm{k}_{\max }=2: \\
3 \\
\lambda_{3 S L S}\end{array}$ & $\begin{array}{l}\text { Computed } \\
\text { adjustment } \\
\text { coefficient } \\
\lambda_{G M M}\end{array}$ & $\begin{array}{c}\text { Error if } \\
\mathrm{k}_{\max }=1: \\
\lambda_{G M M}^{2}\end{array}$ & $\begin{array}{l}\text { Error if } \\
\mathrm{k}_{\max }=2: \\
\lambda_{G M M}^{3}\end{array}$ \\
\hline Fish (03) & -0.19 & & & $0.64 * * *$ & 0.41 & 0.26 \\
\hline Fruit (08) & -0.07 & & & -0.15 & & \\
\hline Beverages (22) & $0.62 * * *$ & 0.38 & 0.24 & $0.58 * * *$ & 0.34 & 0.20 \\
\hline Ores (26) & $0.70 * * *$ & 0.49 & 0.34 & $0.89 * * *$ & 0.79 & 0.70 \\
\hline Wood (44) & $0.46^{* * *}$ & 0.21 & 0.10 & $0.74 * * *$ & 0.55 & 0.40 \\
\hline Wood pulp (47) & $0.37 * * *$ & 0.14 & 0.05 & $0.40^{* * *}$ & 0.16 & 0.06 \\
\hline Copper (74) & $0.80 * * *$ & 0.64 & 0.51 & $0.37 * * *$ & 0.14 & 0.05 \\
\hline
\end{tabular}

Notes: ${ }^{*},{ }^{* *},{ }^{* *}$ denote significance at the 10,5 and 1-percent level, respectively. The adjustment coefficients $\lambda_{3 S L S}$ and $\lambda_{G M M}$ are taken from tables 1 and 2, respectively. 